\section{Structured Descriptive Assessment}

Elizabeth Schoen Simmons

Department of Psychological Sciences, University of Connecticut, Storrs, CT, USA

\section{Synonyms}

SDA

\section{Definition}

A structured descriptive assessment (SDA) uses principles of applied behavior analysis to describe the causes and consequences of a given behavior. A SDA typically occurs in the child's natural environment (e.g., the child's classroom) with no manipulation of environmental variables. The examiner records the antecedent of the child's behavior, target behavior, and consequence. For example, if the child might be engaging in self-harm, the examiner will record the antecedent of this behavior (e.g., the teacher asking a difficult question to the child), the child's behavior (e.g., biting of his hand), and the consequence (e.g., the child is sent out of the classroom with his aide). This type of assessment is often used to determine the cause of maladaptive behavior. It differs from functional behavior analysis as the examiner does not control for environmental variables.

\section{See Also}

- Applied Behavior Analysis

- Functional Behavior Assessment

\section{References and Readings}

Anderson, C., \& Long, E. (2002). Use of a structured descriptive assessment methodology to identify variables affecting problem behavior. Journal of Applied Behavioral Analysis, 35, 137-154.

English, C., \& Anderson, C. (2006). Evaluation of the treatment utility of the analog functional analysis and the structured descriptive assessment. Journal of Positive Behavior Interventions, 8, 212-230.

Sloman, K. N. (2010). Research trends in descriptive analysis. The Behavior Analyst Today, 11(1), 20-35. 